\title{
PRÁTICAS DE CITAÇÃO E MEMÓRIA COLETIVA: APROXIMAÇÕES POSSÍVEIS NA CIEENCIA DA INFORMAÇÃO?
}

\author{
PRÁCTICAS DE CITAS Y MEMORIA COLECTIVA: \\ ENFOQUES POSIBLES EN LA CIENCIA DE LA \\ INFORMACIÓN?
}

\begin{abstract}
Murilo Artur Araújo da Silveira - muriloas@gmail.com Doutorando em Comunicação e Informação pela Universidade Federal do Rio Grande do Sul (UFRGS). Professor da Universidade Federal de Pernambuco (UFPE).

Sônia Elisa Caregnato - sonia.caregnato@ufrgs.br Doutora em Information Studies pela University of Sheffield. Professora da

Universidade Federal do Rio Grande do Sul (UFRGS).

Leilah Santiago Bufrem - santiagobufrem@gmail.com Doutora em Ciências da Comunicação pela Universidade de São Paulo (USP). Professora Visitante Sênior vinculada ao Programa de Pósgraduação em Ciência da Informação da Universidade Federal de Pernambuco (UFPE).
\end{abstract}

\section{RESUMO}

Introdução: Defende o vínculo teórico entre as práticas de citação e as teorias sobre memória coletiva, com vistas ao fortalecimento das relações entre a Ciência da Informação e a Memória Social.

Objetivo: O objetivo do trabalho é discutir sobre as aproximações epistemológicas entre as práticas sociais de citação e as teorias sobre memória coletiva, sob a ótica do paradigma social da Ciência da Informação.

Metodologia: Revisa a literatura sobre as dimensões cognitiva e social das práticas de citação inseridas nos domínios da Comunicação Científica. 
Resultados: Relaciona as práticas de citação e a perspectiva teórica da memória coletiva proposta por Halbwasch, conformando-as no discurso sociocognitivista da Ciência da Informação para fins de formação e manutenção do arquivo das ciências.

Conclusão: A demarcação dos vínculos evidenciou a necessidade de ampliação da discussão sobre as práticas de citação no tocante aos construtos teóricos que deem conta do processo histórico que conduzem à produção de conhecimentos, para fins de visualização da lógica científica.

Palavras-Chave: Citação. Memória coletiva. Ciência da informação. Memória social. Aspectos teóricos.

\section{INTRODUÇÃO}

A ciência e o seu desenvolvimento, juntamente com as formas de comunicação, as configurações que assumem; os relacionamentos estabelecidos entre os membros da comunidade e as manifestações possíveis de seus produtos são tópicos relevantes dos estudos de Comunicação Científica. Os temas, problemas, objetos, objetivos, métodos e técnicas utilizadas, bem como os resultados desses estudos estão, essencialmente, circunscritos nos domínios da Ciência da Informação. As pesquisas dessa especialidade buscam, em larga escala, sinalizar, diacrônica e sincronicamente, a dinâmica científica em várias e múltiplas dimensões.

A demarcação da Comunicação Científica como segmento da Ciência da Informação possibilita interlocuções necessárias com outros campos, orientadas para o entendimento das práticas científicas institucionalizadas quer do ponto de vista cognitivo quer do ponto de vista social. Emergem então, nessa perspectiva, unidades de análise da práxis que se materializam nos produtos científicos, referendados pelas comunidades e instituições. Em decorrência dessa observação sobre a dimensão epistemológica, os produtos da ciência e suas unidades constituintes são os objetos preferenciais da Comunicação Científica, por serem expressões objetivadas e construídas pelos cientistas.

Dentre os objetos contemplados nos estudos de Comunicação Científica, as citações e suas referências são os elementos que revelam as dimensões social e cognitiva de produção do conhecimento científico. Elas representam a movimentação discursiva que todos os pesquisadores realizam para a certificação e aceitação de seus trabalhos, submetendo suas ideias à crítica fundamentada e 
reforçando a lógica das práticas sociais legitimadas pela comunidade. Juntas, a citação e a referência são indexadores semânticos e sociais que sinalizam o nível de produção do conhecimento em diferentes períodos de tempo, suas circunstâncias e adjacências, expressando a dinâmica do processo científico e conferindo originalidade, legitimidade e visibilidade (GLANZEL, 2003; ZIMAN, 1979). Desse modo, o conceito de comunicação científica vem originando discussões sobre formas e desdobramentos das práticas em relação aos níveis de produção e às políticas governamentais, gerando controvérsias relacionadas com as políticas de fomento às atividades científicas e suas decorrências relativas à ênfase quantitativa presente nas avaliações dos órgãos públicos.

A importância da reconstituição do percurso integrador da comunidade científica, pela conformação do registro de ideias passadas para posterior recuperação, determina a posição da citação e das referências, respectivamente, no arquivo da ciência. Sinalizam, assim, as práticas de reconstrução da memória coletiva de comunidades científicas em diversos níveis. Essas práticas sociais são discursivas, elaboradas conforme necessidades e especificidades próprias do grupo, estruturando o processo de comunicação científica e definindo a estrutura das fontes de informação que compõem os estoques (dinâmicos) de memória coletiva.

A noção admitida para memória coletiva está pautada na ideia de reconstrução dinâmica de fluxos de informação de um grupo social em contextos específicos, por meio da articulação entre passado e presente para o futuro, entendida, portanto, como fenômeno do fazer científico. Nessa perspectiva, colocase a citação como elemento científico inserido na pluralidade das práticas sociais cultivadas e legitimadas pela comunidade, que determinam as continuidades e vicissitudes do percurso científico.

Entende-se por práticas sociais das comunidades científicas as ações e os movimentos objetivados de construção e reconstrução do fazer científico delimitado no tempo e espaço. Nesse contexto, a citação é o mecanismo de reconstrução de textos científicos por meio de outros construídos anteriormente, servindo-se de base para reconstruções futuras. Desse modo, as operações temporais e espaciais materializadas no discurso científico, sinalizam o modus operandi das práticas sociais das comunidades científicas.

O viés apresentado encontra aderência epistemológica no paradigma social da Ciência da Informação, na medida em que a citação e a referência se deslocam 
no tempo, materializando-se em diversos textos como elementos de práticas sociais coletivas. As relações são tecidas e sustentadas pelas ações randômicas dos pesquisadores em seus textos, em que passado e presente se encontram, colocando-se em evidência para uso no futuro. Estaria então a citação e as referências no escopo do paradigma social da Ciência da Informação? Seriam a citação e as referências elementos que demonstram a construção coletiva do conhecimento? Essas questões suscitam debates importantes para os estudos de Comunicação Científica, no mesmo instante que permitem aproximações teóricas com o campo da Memória Social.

Nessa perspectiva, o objetivo central do trabalho é discutir sobre as aproximações epistemológicas possíveis entre as práticas sociais de citação e as teorias sobre memória coletiva, sob a ótica do paradigma social da Ciência da Informação. Pretende-se estabelecer vínculos teóricos para os domínios da Comunicação Científica, em conformidade com o modelo paradigmático social estabelecido por Capurro (2003) para a Ciência da Informação. Move esta reflexão o fato de que, embora seja notável o destaque dado aos estudos sobre a produção científica e as modalidades comunicativas presentes nas redes sociais, poucos transcendem os propósitos descritivos do próprio fenômeno. Raros são os textos orientados para as políticas científicas instituídas no país e as práticas delas decorrentes, originadas das relações e configurações que adquiriram essas práticas e do impulso tecnológico que receberam. Os estudos denominados de citatologia ignoram, geralmente, a questão política relacionada às verdadeiras batalhas travadas nos campos culturais, o que os impede de caminhar além das relações mais aparentes, acusam Bourdieu, Chamboredon e Passeron (1968). Detêm-se nas referências explícitas, ou seja, somente na face visível das referências realmente efetuadas, tanto para o produtor como para o público. Sua função tem sido determinar índices de conhecimento, podendo definir eventualmente relações de lealdade ou dependência.

A reivindicação principal para a interlocução é, por um lado, fortalecer as conexões e os limites entre o campo da Memória Social e a Ciência da Informação e, do outro, oferecer novas bases teóricas para compreensão das práticas de citação em diferentes contextos. Nesse horizonte, é importante destacar que tais relações servirão para orientar novos estudos que contemplem a natureza memorial das práticas de citação. Busca-se ainda uma aproximação com o campo da Memória 
Social com o intuito de reforçar os esforços diacrônicos e sincrônicos da produção de conhecimentos dos distintos campos da ciência. Representa, portanto, o lançamento de novos olhares e perspectivas para o entendimento e resolução dos problemas de produção, disseminação e uso da informação.

Após as considerações iniciais, as próximas seções discutirão: a) as práticas de citação e os reflexos dessas ações para o sistema de comunicação científica, tendo em vista as posições assumidas no arquivo da ciência e na produção do conhecimento; b) as interlocuções possíveis entre o conceito de memória coletiva e as práticas de citação, buscando a integração de interesses entre os campos relacionados.

\section{AS PRÁtICAS DE CITAÇÃO E O SISTEMA DE COMUNICAÇÃO CIENTÍFICA}

O domínio da Comunicação Científica sob o enfoque da Ciência da Informação é formado por aportes teórico-metodológicos bem delimitados e seus resultados ilustram as formas, os contextos e os usos dos produtos da ciência, sustentado por relações integradas com outros domínios da área. Seu propósito enquanto domínio científico é investigar os processos de produção, comunicação e uso da informação científica e tecnológica registrada, justificado pela dimensão política, social, econômica, histórica e cultural das práticas dos pesquisadores, por meio de objetos de análises diversos e distintos.

A citação, no contexto da Comunicação Científica, resulta de uma experiência seletiva como expressão individual ou coletiva e se concretiza em dada conjuntura de relações sociais. Ela indica uma ação de conexão de ideias entre textos que os pesquisadores realizam no momento da produção de textos científicos, com vistas à sua publicação (MEADOWS, 1999). O princípio do vínculo de ideias é ilustrar a linhagem histórica da produção do conhecimento, de forma integrada, entre os textos produzidos com os que estão sendo, tornando-se disponível, a posteriori, para os que serão. Essa prática de vinculação é, para Compagnon (2007), a representação de recortes e colagens entre partes de textos para a constituição de um novo, que demonstra a reconfiguração das ideias, dos pensamentos objetivos e da autoria. Nesse processo de reconstrução, o novo texto intercruza os vários 
discursos recortados que se conformam em colagens articuladas e coesas, vinculando os diversos autores numa rede improvável de se imaginar, porém possível, por meio do novo texto. Por sua vez, esse texto produzido, ao ser comunicado, estará disponível para novos recortes, e dialogará com outros recortes, conectando-se por meio de colagens, tantas quais forem possíveis e improváveis (COMPAGNON, 2007). Com opinião complementar, Mostafa e Máximo (2003, p. 97) afirmam que "as citações devem ser compreendidas como unidade de análise por representarem a 'visita' ou a 'consulta' ou o 'detour' que todo pesquisador faz ao produzir conhecimento". Para os autores, a visita é sempre realizada pelo pesquisador para os seus antecessores e à sua produção, determinando a seguinte situação:

[...] o outro na dialética hegeliana seria a negação momentânea de si para o reencontro em si com o outro no caminho de volta. O outro nos acompanha no caminho de volta sempre que o citamos em nossas referências (bibliográficas). Nós nos referimos ao outro para produzir conhecimento, no mesmo movimento em que nós oferecemos a ele (MOSTAFA; MÁXIMO, 2003, p. 97).

Esse contexto expressa a diversidade e o dinamismo das atividades sociais na ciência, em que o autor e suas ideias, advindas do processo de pesquisa, ao se registrarem, colocam em evidência as citações e as referências como elementos essenciais do arquivo científico. Resultante do direito inerente a qualquer autor de se referir aos textos de outro, a citação pressupõe um juízo de valor, um discernimento que pode traduzir caução teórica, aprovação ou até desaprovação. Mas, mesmo neste último caso, a referência traduz o reconhecimento de que o autor citado é autoridade no campo específico do saber sobre o qual versa e faz parte de um contexto em que as manifestações críticas são determinantes para o aprimoramento dos resultados do trabalho intelectual. $O$ registro desses elementos em um texto busca cumprir, não somente uma função documental, que aponta a trajetória histórica percorrida pelos pesquisadores, mas também reforçar as práticas sociais necessárias para manutenção do padrão do fazer científico. Desse modo, o texto e seus elementos constitutivos (dentre eles, as citações e as referências) exercem uma função social no sistema de comunicação científica, não apenas por disseminar o conhecimento produzido, como também por ser o estoque daquele, integrando assim o que se denomina arquivo da ciência (MUELLER, 2003). 
Para explicar a noção de arquivo da ciência que norteia este trabalho, recorrese a Foucault (2000) por meio da obra A Arqueologia do Saber, que determina a natureza da arqueologia como a atividade de descrição do arquivo. Por seu turno, o arquivo sobre o qual o autor discute, é composto por discursos organizados dos diversos fazeres, registrados e comunicados, que se tornam disponíveis para a formação e constituição de novos discursos. Nessa dimensão epistemológica, o arquivo, além de sua função histórica, adquire outras funções: arqueológica, mnemônica, documental, entre outras, e se projeta para distintos contextos sociais de forma contínua e progressiva. Entendem-se então, como arquivo da ciência, os discursos pronunciados e os veículos disseminadores dos discursos, inscritos em um suporte e efetivamente comunicados, que revelam a dinâmica dos conhecimentos produzidos e das práticas realizadas por uma comunidade científica. Para Kobashi e Santos (2008), os arquivos da ciência, sob o ponto de vista da Ciência da Informação, são instrumentos de pesquisa úteis para reconstruir e reavaliar os conhecimentos disponíveis, por meio da descrição dos seus elementos constitutivos que geram indicadores multidimensionais. $O$ contexto desse arquivo, entretanto, não é pacífico, pois comporta a existência de grupos competidores, ocupantes de diversas posições em um determinado campo da produção cultural, todos em busca da legitimidade atribuída pelas instâncias de consagração.

No limite conceitual e empírico apontado, o arquivo da ciência pode ser delimitado em duas perspectivas: a) macroestrutura: as bases de dados, os periódicos, os anais de eventos, as teses e dissertações, os livros e manuais, entre outros; b) microestrutura: a autoria e as filiações, os títulos e resumos, as palavraschave e os temas, as citações e referências, e outras estruturas textuais. Em outras palavras, o arquivo da ciência é o que Mueller (2003) denomina como literatura científica: os produtos da ciência são os instrumentos de disseminação dos conhecimentos oriundos do processo de pesquisa e que refletem, indubitavelmente, os preceitos e normas construídos e legitimados pela comunidade, constituindo-se como um sistema. Nessa relação entre literatura e comunidade, o arquivo da ciência organiza e reorganiza as práticas e os produtos, de acordo com os aportes teóricos e metodológicos, evidenciando o ciclo contínuo do processo de comunicação científica.

Diante do exposto, a citação e as referências se situam na microestrutura do arquivo da ciência com funções delimitadas no processo de comunicação e 
conformadas na macroestrutura. As duas unidades estabelecem operações de reconhecimento de ideias (citação) e conhecimento das fontes (referências) que se materializam em texto, expressando vínculos semânticos e sociais com o arquivo científico (NORONHA; FERREIRA, 2003; WOUTERS, 1999). As operações efetuadas e suas possibilidades estão condicionadas às práticas de apreensão de conteúdos (vínculo semântico) dos estoques e das formas de registro aceitas (vínculo social) pela comunidade, criando a cultura da citação. Para Wouters (1999), a cultura da citação é a manifestação científica que interliga comunidade e literatura, revela apropriação e acesso à informação, respectivamente, e ainda promove a articulação de ideias disponíveis no passado e com as do presente, projetando-se para o futuro. Essa projeção permite: a) visualizar as conexões objetivas e subjetivas esperadas e improváveis, b) perpetuar ações e valores, regras e normas de conduta de um grupo social e; c) revitalizar o fazer científico e as práticas das instâncias e dos atores envolvidos (WOUTERS, 1999).

A perspectiva lançada coloca a citação e as referências no centro de um conjunto de práticas desenvolvidas e sustentadas por uma comunidade, aproximando-se da corrente paradigmática sociocognitiva apresentada por Capurro (2003) para a Ciência da Informação. Em linhas gerais, o entendimento sobre o paradigma social versa sobre os processos de construção do conhecimento, as formas e os instrumentos, os contextos e as relações, posicionando o indivíduo não somente como produtor e consumidor, mas também como agente de disseminação de informações. Nessa posição, o autor, ao comunicar sua obra ao público, cumpre determinadas práticas de um itinerário consagrador, definido pelas relações existentes no âmbito da sua área de atuação, de modo a assegurar um modo especial de consagração situado numa dimensão mais simbólica do que propriamente material e, portanto, relativa ao âmbito da economia que Bourdieu relacionou às chamadas trocas simbólicas (BOURDIEU, 1976).

Dito desta forma, as atividades ligadas à produção, comunicação e uso da informação, dentre outras, são realizadas em colaboração e apoiadas pelos componentes tecnológicos existentes, com demarcações tênues entre elas. Nesse horizonte, destaca-se o indivíduo, seus contextos e suas interações, tornando a construção do conhecimento coletiva. 


\section{AS PRÁtICAS DE CITAÇÃo E A MEMÓRIA COLETIVA: DIÁlOGOS POSSÍVEIS?}

A citação enquanto recurso integrador de textos do passado com os do presente ilustra uma construção original de fragmentos discursivos que se acomodam em uma nova construção textual. O novo texto demonstra um processo científico de reconstrução (individual ou coletiva) única e alinhada ao estoque de conhecimentos compartilhados consensualmente pela comunidade. Nessa perspectiva, a citação, e consequentemente as referências, encontram aderência teórica nos pressupostos epistemológicos da Memória Social, em especial às premissas teóricas de constituição da memória coletiva.

A ideia admitida neste ensaio para memória coletiva é a de reconstrução de fatos, acontecimentos e momentos históricos por meio dos discursos efetivamente pronunciados pelos testemunhos, e agenciados por um grupo social como produto de construção coletiva (COMPAGNON, 2007; HALBWASCH, 2006). A reconstrução procede no nível do agenciamento das múltiplas vozes que compõem o grupo social, culminando em uma única voz, sedimentada nas bases dos saberes e fazeres do contexto criado e amplificada para uso ou descarte de/em outros contextos, conforme necessidades ou justaposições. Por sua vez, o agenciamento seria a conformação dos discursos concordantes e discordantes realizados pelos atores do grupo social em um único discurso, formatado no consenso e delimitado no espaço e tempo da reconstrução. Como resultado, tem-se o produto oriundo das ações dos sujeitos pertencentes a uma comunidade, reorganizado coletivamente para 0 cumprimento de uma função social (HALBWASCH, 2006).

Ao aproximar o conceito adotado de memória coletiva e as práticas de citação, percebe-se o alinhamento dos fenômenos no que se refere à reconstrução de discursos pronunciados que se materializam na dimensão espaço-temporal por meio de ações coletivas. Percebe-se também que a materialização desses discursos reconstruídos possibilita a constituição de arquivos (da memória, da história, da ciência, entre outros), disponibilizando as fontes de informação para os devidos usos (COSTA, 1997).

Cabe ressaltar, porém, que os usos das fontes de informação constantes nos arquivos não podem ser considerados como estoques absolutos, necessitando de 
postura crítica, pautada na reflexão do que os nossos antepassados fizeram de nós, não aceitando, simplesmente, o que eles fizeram. Como consequência, surgem novos discursos sustentados por análises contextualizadas dos discursos anteriores, garantindo o processo de reconstrução da memória (COSTA, 1997).

Para estabelecer as conexões entre memória coletiva e as práticas de citação, recorre-se ao pensamento de Eugene Garfield (1974) de que é por meio da citação que se pode perceber a dinâmica do processo científico. Esse fenômeno é conduzido pela reformulação das contribuições anteriores, na forma de apoio ou refutação, parcial ou total, que resulta em uma nova, proporcionada pelas menções (citações) registradas nessa nova contribuição (texto) (GARFIELD, 1974; SMALL, 1999). Logo, esse novo texto (discurso) revela a passagem reflexiva realizada através das citações (arquivos) aos textos anteriores (arquivos), conjugando diacronicamente $\mathrm{o}$ passado e o presente, configurando-se assim, em uma reconstrução coletiva da memória científica. A Figura 1 mostra a representação do fluxo de reconstrução da memória da ciência proporcionado pelas as citações e suas referências. 
Figura1- Mapa de Visualização Cronológica e Lista Respectiva dos 15 Trabalhos mais Vinculados na Web of Science, no tema Competência Informacional.

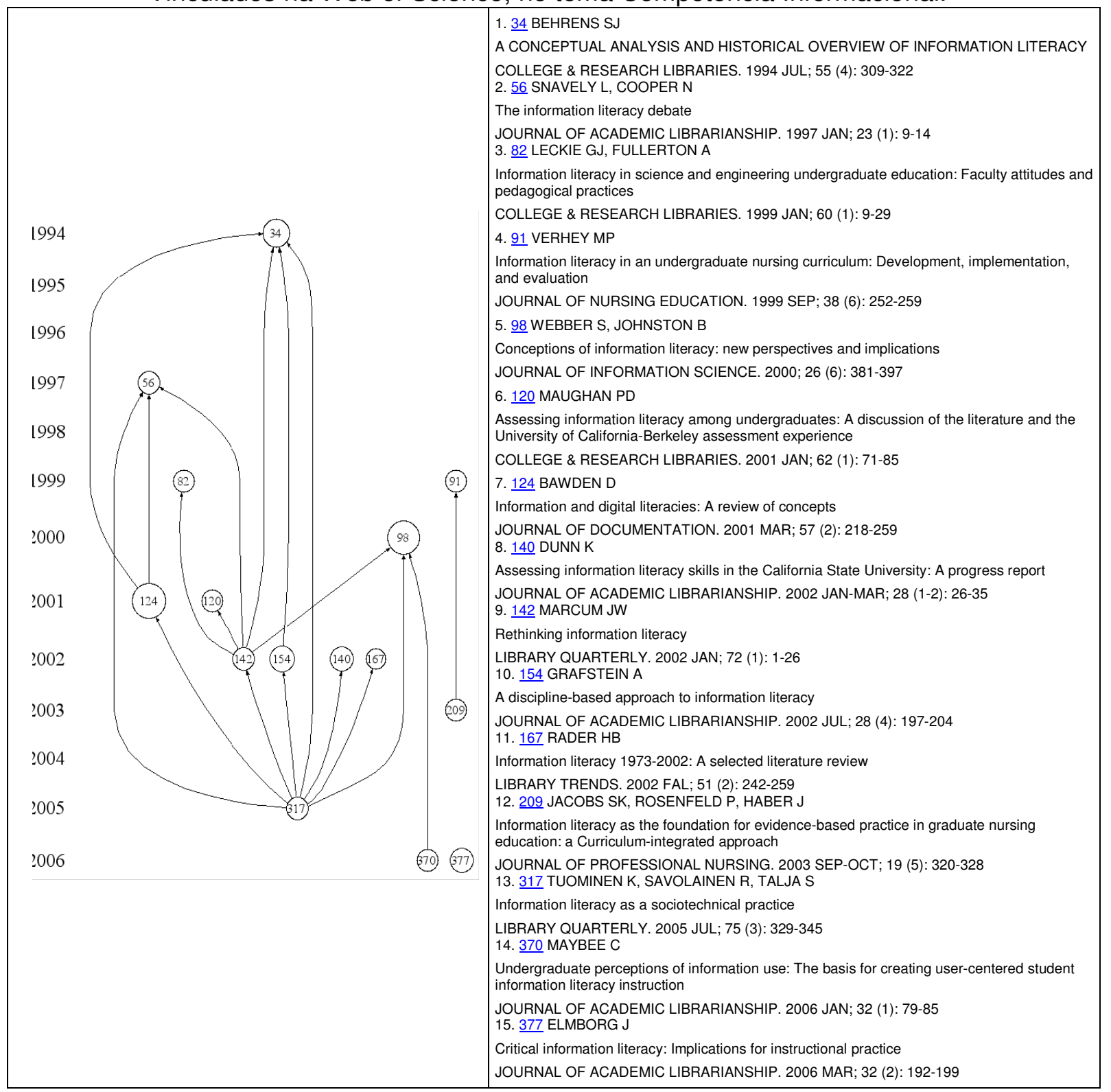

Fonte: Adaptado de Web of Science (2012).

A ilustração identifica na Web of Science os quinze artigos com os maiores vínculos no conjunto de todos os artigos indexados na base sobre a temática competência informacional, demonstrando as reconstruções possíveis no período analisado. Os vínculos denotam as ligações entre as menções em nível global por meio de todos os artigos presentes na base, resultado da dinâmica da produção coletiva de conhecimento, fundamentados no exercício da crítica científica. Portanto, são articulações formuladas no seio da ciência, expressas através da conexão entre passado e presente, tornando-se fonte de informação para conexões futuras, condizentes com preceitos e regras de comunicação científica. 
Diante do exposto, presume-se que essa produção coletiva do conhecimento por meio das citações e referências inspirou Garfield (1974) a criar o que hoje se conhece por Web of Science. Em artigo de sua autoria, ele aponta as formas de integração dos saberes entre a Biblioteconomia e a História da Ciência, para fins de visualização dos caminhos percorridos, dos fragmentos percebidos e esquecidos, e também da trajetória futura das diversas especialidades científicas, em regime de cooperação numa perspectiva historiográfica. Explica que o processo de desenvolvimento historiográfico das ciências se concretiza por meio dos registros materializados, em que discursos e atos científicos se conformam, aglutinando-se de forma espontânea ou induzida, conforme regras e ditames do grupo e das instituições sociais (GARFIELD, 1974).

Wouters (1999) expressa que as práticas de citação são constituídas por meio das atividades de seleção e descarte, estando estas amparadas em pertinências textuais e científicas, preferências individuais e coletivas e pressões sociais. Nesses níveis de operação, as práticas de citação se ritualizam, tornando-se discriminatórias em sua concepção e viciadas em sua execução. Como consequência científica temse o esquecimento bibliográfico de contribuições significativas, a distorção entre as condutas ideal e real dos pesquisadores, e ainda o reforço e a perpetuação de posições ideológicas, tanto individual quanto coletiva.

As ações para reavivar ou esquecer o outro tornam-se nitidamente compreensíveis à luz de Bourdieu (1976, p. 59), quando afirma que a verdade de um fenômeno cultural, aqui se privilegiando a citação, "depende do sistema de relações históricas e sociais no qual ele se insere". O autor visa especialmente esclarecer que essas práticas comunicativas do pesquisador são afetadas pelas suas condições de existência e que sua legitimação decorre das relações que os produtores de bens simbólicos mantêm entre si. Se considerada a produção científica como bem simbólico, percebe-se que as diferentes posições em um de seus campos específicos geram grupos de competição pela legitimidade de atuação no referido campo. Para o estudo do fenômeno, é possível uma dupla leitura: a do campo cultural propriamente dito e a do campo político, que analisa as estratégias mais ou menos conscientes, em direção ao campo amigo ou inimigo. A reflexão coincide com a posição de Wouters (1999) sobre as ações de seleção e descarte orientadas por práticas discriminatórias de citação geradas pelas preferências individuais ou coletivas e pelas pressões políticas e sociais. 
No tocante às considerações tecidas sobre as práticas de citação, 0 empreendimento planejado e executado por Garfield evidencia o comportamento, a incidência e a distribuição das menções efetuadas, possibilitando visualizar o percurso trilhado por todos os segmentos envolvidos. Contudo, os aspectos direcionados à subjetividade das práticas de citação, tão importante quanto os objetivos, não foram contemplados nos instrumentos e aplicações da Web of Science, cabendo a realização de análises, interpretações e críticas documentadas pelos especialistas, a posteriori. Nessa perspectiva, a Web of Science se configura como um robusto sistema de informação que interliga passado e presente por meio de conexões entre textos, desenhando uma rede possível, improvável e material dos registros efetuados a ciência.

Chama-se atenção para os elementos subjetivos que tangenciam as práticas de citação, para expressar que investigações acerca desses são fundamentais na medida em que podem sinalizar não somente os desvios, os problemas e as deficiências, mas também apontar as possibilidades e potencialidades dos fluxos de informação para reconstrução da memória. Isso porque motivações políticas ou pessoais originam ações discriminatórias e seletivas podendo tanto reforçar quanto enfraquecer o sucesso dessa reconstrução, não apresentando, portanto, o mesmo poder junto àqueles pares do campo de produção dos bens legítimos. Como desdobramentos, espera-se a reconfiguração de construções coletivas em múltiplas direções, tanto do que fizeram quanto do que deixaram de fazer, para fins de ampliação das percepções dos conhecimentos produzidos.

\section{CONSIDERAÇÕES FINAIS}

As reflexões realizadas sinalizam questões de ordem científica acerca da repercusão advinda do mecanismo de citar e referenciar no âmbito da ciência, na busca do estabelecimento de relações e distinções entre a Ciência da Informação e a Memória Social. A demarcação das práticas de citação para a Comunicação Científica necessitam de construtos teóricos que deem conta do processo histórico que conduzem à produção de conhecimentos, para fins de visualização da lógica científica. Nesse sentido, a visita às teorias de memória coletiva foram fecundas porque inseriu as práticas de citação no modelo de reconstrução coletiva da 
memória científica, ancorada na corrente paradigmática sociocognitiva da Ciência da Informação.

Convém esclarecer que o trabalho é resultante das primeiras leituras sobre os tópicos temáticos envolvidos, na busca do entendimento das questões norteadoras das ações empreendidas pelas comunidades científicas quando citam e referenciam. Logo, não se busca o ineditismo das ideias perante a relação estabelecida, sobretudo pela incipiência de reflexões verticalizadas para a formulação dos fundamentos teóricos das práticas de citação, pois, possivelmente, alguém já realizou esforços nessa vinculação. Dito isto, sugere-se ainda a discussão sobre a conjugação entre o presente e o futuro das práticas de citação, na medida em que elas refletem a distinção entre memória e conhecimento, sob os domínios da Ciência da Informação.

\section{REFERÊNCIAS}

BOURDIEU, Pierre. A economia das trocas simbólicas. São Paulo: Perspectiva. 1976.

BOURDIEU, Pierre; CHAMBOREDON, Jean-Claude; PASSERON, Jean-Claude. Le metier de sociologue. Paris: Mouton-Bordas, 1968.

CAPURRO, Rafael. Epistemologia e Ciência da Informação. In: ENCONTRO NACIONAL DE PESQUISA EM CIÊNCIA DA INFORMAÇÃO, 5., 2003, Belo Horizonte. Anais eletrônicos... Belo Horizonte: ANCIB, 2003.

COMPAGNON, Antoine. $\mathbf{O}$ trabalho da citação. Belo Horizonte: Ed. Universitária da UFMG, 2007.

COSTA, Icléia Thiesen Magalhães. Memória institucional: a construção conceitual numa abordagem teórico-metodológica. 1997. 161f. Tese (Doutorado em Ciência da Informação) - Instituto Brasileiro de Informação Científica e Tecnológica, Rio de Janeiro, 1997.

FOUCAULT, Michel. Arqueologia das ciências e história dos sistemas de pensamento. Rio de Janeiro: Forense, 2000.

GARFIELD, Eugene. Historiographs, Librarianship and the history of science. Currents Contents, v. 38, p. 136-150, 1974. 
GLANZEL, Wolfgang. Bibliometrics as a research field: a course on theory and application of bibliometric indicators. Course Handouts, 2003. Disponível em:<http://nsdl.niscair.res.in/ jspui/bitstream/123456789/968/1/Bib_Module_KUL.pdf>. Acesso em: 12 set. 2014.

HALBWASCH, Maurice. A memória coletiva. São Paulo: Centauro, 2006.

KOBASHI, Nair Yumiko; SANTOS, Raimundo Nonato Macedo dos. Arqueologia do trabalho imaterial: uma aplicação bibliométrica à análise de dissertações e teses. Encontros Bibli, Florianópolis, n. esp. p. 106-115, 2008.

MEADOWS, Arthur Jack. A comunicação científica. Brasília: Briquet de Lemos, 1999.

MOSTAFA, Solange Puntel; MÁXIMO, Luis Fernando. A produção científica da Anped e da Intercom no GT da educação e comunicação. Ciência da Informação, Brasília, v. 32, n. 1, p. 96-101, 2003.

MUELLER, Suzana Pinheiro Machado. A ciência, o sistema de comunicação científica e a literatura científica. In: CAMPELLO, Bernadete Santos; CENDÓN, Beatriz Valadares; KREMER, Jeannette Marguerite (Org.). Fontes de informação para pesquisadores e profissionais. Belo Horizonte: Ed. da UFMG, 2003. p. 2134.

NORONHA, Daisy Pires; FERREIRA, Sueli Mara Soares Pinto. Índices de citação. In: CAMPELLO, Bernadete Santos; CENDÓN, Beatriz Valadares; KREMER, Jeannette Marguerite (Org.). Fontes de informação para pesquisadores e profissionais. Belo Horizonte: Ed. da UFMG, 2003. p. 246-262.

SMALL, Henry. Visualizing science by citation mapping. Journal of the American Society for Information Science, Washington, v. 50, n. 9, p. 799-813, 1999.

WOUTERS, Paul. The citation culture. 1999. 278f. Tese (Doutorado em Ciências) University of Amsterdan, Amsterdan, 1999.

ZIMAN, John. Conhecimento público. Belo Horizonte: Itatiaia; São Paulo: EDUSP, 1979. (O Homem e a Ciência, v. 8).

Title

Citation practices and collective memory: possibles approaches in information science?

\section{Abstract}

Introduction: It defends the theoretical link between citation practices and theories about collective memory, in order to strengthen the relations between Information Science and Social Memory. 
Objective: The objective is to discuss the epistemological approaches between social practices of citation and theories of collective memory, from the perspective of social paradigm of Information Science.

Methodology: It reviews the literature on cognitive and social dimensions of citation practices in the fields of Scientific Communication.

Results: It also establishes a relationship between citation practices and the theoretical perspective of collective memory proposed by Halbwasch, by conforming them to the sociocognitivista perspective in Information Science in order to improve training and maintenance of sciences archives.

Conclusion: The demarcation of the links highlighted the need to expand the discussion of citation practices in relation to theoretical constructs that give account of the historical process leading at production of knowledge, for the purpose of visualization of scientific logic.

Keywords: Citation. Collective memory. Information science. Social memory. Theoretical perspective.

\section{Título}

Prácticas de citas y memoria colectiva: enfoques posibles en la ciencia de la información?

\section{Resumen}

Introducción: Defiende el vínculo teórico entre las prácticas de citas y las teorías sobre memoria colectiva, buscando fortalecer las relaciones entre la Ciencia de la Información y de la Memoria Social.

Objetivo: El objetivo es discutir los enfoques epistemológicos entre las prácticas de citas sociales y las teorías de la memoria colectiva, por medio de la perspectiva del paradigma social de la Ciencia de la Información.

Metodología: Revisa la literatura sobre las dimensiones cognitivas y sociales de las prácticas de citas insertadas en el ámbito de la Comunicación Científica.

Resultados: Relaciona las prácticas de citas y la perspectiva teórica de la memoria colectiva que propone Halbwasch, conforme el paradigma sociocognitivista de la Ciencia de la Información, para la formación y el mantenimiento de los archivos científicos.

Conclusíon: La delimitación de los enlaces destacó la necesidad de ampliar la discusión sobre las prácticas de citas en relación las construcciones teóricas que dan cuenta del proceso histórico que conducen a la producción de conocimiento, a los efectos de la visualización de la lógica científica.

Palavras-Chave: Citas. Memoria colectiva. Ciencia de la información. Memoria social. Aspectos teóricos.

Recebido em: 23.02.2014

Aceito em: 17.12.2014 